\title{
Potential of DosR and Rpf antigens from Mycobacterium tuberculosis to discriminate between latent and active tuberculosis in a tuberculosis endemic population of Medellin Colombia
}

\author{
Leonar Arroyo ${ }^{1}$, Diana Marín ${ }^{2}$, Kees L. M. C. Franken ${ }^{3}$, Tom H. M. Ottenhoff ${ }^{3}$ and Luis F. Barrera ${ }^{1,4^{*}}$
}

\begin{abstract}
Background: Tuberculosis (TB) remains one of the most deadly infectious diseases. One-third to one-fourth of the human population is estimated to be infected with Mycobacterium tuberculosis (Mtb) without showing clinical symptoms, a condition called latent TB infection (LTBI). Diagnosis of Mtb infection is based on the immune response to a mixture of mycobacterial antigens (PPD) or to Mtb specific ESAT-6/CFP10 antigens (IGRA), highly expressed during the initial phase of infection. However, the immune response to PPD and IGRA antigens has a low power to discriminate between LTBI and PTB. The T-cell response to a group of so-called latency (DosR-regulon-encoded) and Resuscitation Promoting (Rpf) antigens of Mtb has been proved to be significantly higher in LTBI compared to active TB across many populations, suggesting their potential use as biomarkers to differentiate latent from active TB.

Methods: PBMCs from a group LTBI $(n=20)$ and pulmonary TB patients (PTB, $n=21)$ from an endemic community for TB of the city of Medellín, Colombia, were in vitro stimulated for 7 days with DosR- (Rv1737c, Rv2029c, and Rv2628), Rpf(Rv0867c and Rv2389c), the recombinant fusion protein ESAT-6-CFP10 (E6-C10)-, or PPD-antigen. The induced IFNy levels detectable in the supernatants of the antigen-stimulated cells were then used to calculate specificity and sensitivity in discriminating LTBI from PTB, using different statistical approaches.

Results: IFNY production in response to DosR and Rpf antigens was significantly higher in LTBI compared to PTB. ROC curve analyses of IFNy production allowed differentiation of LTBI from PTB with areas under the curve higher than 0.70 . Furthermore, Multiple Correspondence Analysis (MCA) revealed that LTBI is associated with higher levels of IFNy in response to the different antigens compared to PTB. Analysis based on decision trees showed that the IFNy levels produced in response to Rv2029c was the leading variable that best-classified disease status. Finally, logistic regression analysis predicted that IFNy produced by PBMCs in response to E6-C10, Rv2029c, Rv0867c (RpfA) and Rv2389c (RpfA) antigens correlates best with the probability of being latently infected.
\end{abstract}

Conclusions: The Mtb antigens E6-C10, Rv2029c (PfkB), Rv0867c (RpfA) and Rv2389c (RpfA), may be potential candidates to discriminate LTBI from PTB.

Keywords: Tuberculosis, Latency, DosR, Rpf, IFNy biomarkers

\footnotetext{
* Correspondence: luis.barrera@udea.edu.co

'Grupo de Inmunología Celular e Inmunogenética (GIClG), Albinusdreef 2,

2333 Leiden, ZA, Netherlands

${ }^{4}$ Instituto de Investigaciones Médicas, Facultad de Medicina, Universidad de

Antioquia, UdeA, Calle 70 No. 52-21, Medellín, Colombia

Full list of author information is available at the end of the article
}

(c) The Author(s). 2018 Open Access This article is distributed under the terms of the Creative Commons Attribution 4.0 International License (http://creativecommons.org/licenses/by/4.0/, which permits unrestricted use, distribution, and reproduction in any medium, provided you give appropriate credit to the original author(s) and the source, provide a link to the Creative Commons license, and indicate if changes were made. The Creative Commons Public Domain Dedication waiver (http://creativecommons.org/publicdomain/zero/1.0/) applies to the data made available in this article, unless otherwise stated. 


\section{Background}

Tuberculosis (TB) continues to be one of the deadliest infectious diseases. In 2015 WHO reported an increase in the world prevalence and mortality rate of active tuberculosis (TB) disease cases [1], particularly in the developing world. Latent TB infection (LTBI), defined as the absence of clinical symptomatology in the presence of infection, affects an estimated one-third to one-fourth of the human population [2], and as a result of reactivation disease represents the primary source of active TB.

LTBI is traditionally identified as a positive reaction $(>5-$ $10 \mathrm{~mm}$ induration) in response to the intradermal injection of a protein purified extract of Mycobacterium tuberculosis $(M t b)$, named tuberculin | [3]. Although sensitive, the specificity of the intradermal reaction is compromised by previous vaccination with $M$. bovis BCG and/or infection with some non-tuberculous mycobacteria (NTM) [4]. More recently, the Interferon Gamma Release Assays (IGRAs) have contributed to a higher specificity in detection of Mtb infection since these assays utilize proteins encoded in the $M t b$, but not in the BCG genome, such as ESAT- 6 and CFP10 [5-8]. Nevertheless, both assays have demonstrated a low predictive value for progression to the active forms of TB $[9,10]$.

During the last few years, in vivo and in vitro evidence has indicated that $M t b$ adapts its transcriptional signature to the microenvironmental conditions posed by the host cells, such as macrophages and dendritic cells, and in granulomas of the infected host [11-14]. In addition, these transcriptional changes seem to be necessary for infection establishment $[11,12]$. In conditions such as hypoxia, acidic $\mathrm{pH}$, nutrient starvation, and high concentrations of oxygen (ROIs) and nitrogen (RNIs) reactive intermediates and $\mathrm{CO}_{2}$ that may all be present inside granulomas [15, 16], Mtb requires a group of approximately 50 genes known as the dos $R$ regulon $[11,13,17]$ to survive and enter dormancy. Indeed, the expression of $\operatorname{dos} R$ regulon encoded genes has been associated with the non-replicative persistence of $M t b[11,12]$, showing that some members of this regulon are playing an important role in the maintenance of the latency condition. On the other hand, a family of five genes able to induce resuscitation of dormant bacilli, termed resuscitationpromoting factors ( $r p f$ ), has also been identified in the $M t b$ genome [18]. It has been described that the proteins encoded by the $r p f$ genes ( $r p f \mathrm{~A}-\mathrm{E}$ ) are capable of stimulating the mycobacterial growth of non-replicating cells obtained in vitro $[18,19]$ and play a significant role in the in vivo persistence and reactivation of chronic infection in mice [20, 21]. Additionally, ex vivo studies, have demonstrated that Rpf proteins increased the recovery of $M t b$ from sputum of the patient with active TB [22] and improved the sensitivity of culture-based Mtb test in samples that require long culture times [23].
Given the interest in proteins encoded by the $d o s R$ regulon and the rpf genes, the cellular immune response to some of these members has been studied in different human populations of Africa, Asia, Europe, and America, demonstrating significantly increased responses of LTBI individuals compared to active TB [24-36]. Our studies in a TB endemic community in the city of Medellín, Colombia, have also provided evidence that the dosR encoded Rv1737c (NarK, nitrate reductase), Rv2029c (PFKB, phosphofructokinase B), the hypothetical protein $\mathrm{Rv} 2628$, and the resuscitation-promoting factors (Rpf), Rv0867c (RpfA) and Rv2389c (RpfD), induced higher production of IFN $\gamma$ and a higher frequency of T-cells with a $\mathrm{CD}_{4} 5 \mathrm{RO}^{+} \mathrm{CD} 27^{+}(\mathrm{Tcm})$ phenotype in 7-day stimulation assays of peripheral blood mononuclear cells (PBMCs) of LTBI compared to active TB $[29,30,33]$. Interestingly, this higher response of PBMC from LTBI compared to active TB to Rv1737c, Rv2029c and Rv2628 has also been observed in Africa, Asia, Europe, India and Brazil [24-27, 37], suggesting an immune response independent of the human genetic and environmental background, and possibly of the circulating $M t b$ strains, and thus suggesting the presence of a prevalent immune response to DosR antigens in LTBI.

Given the problems of sensitivity and specificity associated with the immune response to ESAT-6 and CFP10 $M t b$ antigens, the search for immune response biomarkers that more efficiently classify LTBI from active TB is a top priority for the prevalence and incidence of active TB to be reduced. In this study, using variables of the immune response, Receiver Operating Characteristics (ROC curves), CHi-squared Automatic Interaction Detection (CHAID) and logistic regression (LR), we found that the Rv2029c antigen of $M t b$ is a novel classifier of LTBI vs. active TB with high specificity and sensitivity.

\section{Methods \\ Study population}

The study population included two groups of individuals: 20 household contacts ( $\mathrm{HHC}$ ) of recently diagnosed (within 2 weeks) pulmonary tuberculosis patients (PTB), and 21 PTB. The HHC were selected from a previous cohort of HHC from PTB, based on their positive response ( $\geq 22 \mathrm{pg} /$ $\mathrm{ml}$ ) to the CFP10 antigen of $M t b$ and the absence of clinical symptoms compatible with clinical TB [38]. The selected HHC have remained healthy for more than 5 years after the incident case diagnostics (long-term LTBI, ltLTBI), and have not received anti-TB treatment accordingly to the Colombian Minister of Health regulations. The active TB status was confirmed microscopically, by detection of acid-fast bacilli (AFB) on sputum smears at the local TB control program's laboratories, for all TB cases included in the study. The Mycobacterium bovis BCG vaccination status was determined based on the identification of the typical scar left 
after previous vaccination. The blood samples collected from the participants were taken after reading and acceptance of the informed consent forms. This study was approved by the Ethics Committee, Instituto de Investigaciones Médicas, Facultad de Medicina, Universidad de Antioquia (Medellín-Colombia).

\section{Regents}

RPMI-1640 and Dulbecco's PBS (DPBS) were obtained from GIBCO (Grand Island, NY); Ficoll-Hypaque, and penicillin-streptomycin solution from Bio-Whittaker (Walkersville, MD); dimethyl sulphoxide (DMSO); pooled human serum (PHS) from Invitrogen (Brown Deer, WI; Eugene, $\mathrm{OR})$.

\section{Mycobacterial antigens}

Three dosR regulon-encoded (Rv1737c, Rv2029c, Rv2628), two Resuscitation Promoting (Rv0867c and Rv2389c) antigens from Mycobacterium tuberculosis (Mtb), recognized as immunogenic in a previous study [29], and the RD1 fusion Protein ESAT6-CFP10 (E6-C10) were used in the present study. The recombinant proteins were produced and QC-ed by CLMCF and THMO. The production, quality control, preparation and storage of the antigens was previously described [24, 39]. Briefly, genes were amplified by PCR and cloned by Gateway Technology (Invitrogen, San Diego, CA) in a bacterial expression vector containing an $\mathrm{N}$-terminal histidine tag. The proteins were overexpressed in Escherichia coli BL21(DE3) and purified, as described previously [40]. Purity and size were checked by gel electrophoresis and Western blotting with anti-His antibodies and anti-E. coli antibodies. Residual endotoxin levels were determined by a Limulus amebocyte lysate assay (Cambrex) and were found to be below $50 \mathrm{IU} / \mathrm{mg}$ recombinant protein. Recombinant antigens were freezedried and shipped at ambient temperature to the Colombian research site, prepared as described [40] aliquoted and stored at $-80{ }^{\circ} \mathrm{C}$ until further use. The purified protein extract (RT50) (PPD) from Staten Serum Institute (Copenhagen, Denmark) was also used in this study.

\section{Isolation of peripheral blood mononuclear cells (PBMCs) and culture conditions}

The procedure to obtain and culture conditions for peripheral blood mononuclear cells (PBMCs) were previously described [29, 30, 33]. Briefly, PBMCs were collected from sodium heparin anticoagulated venous blood $(10 \mathrm{ml})$ and separated by Ficoll-Hypaque density gradient centrifugation. PBMC were washed twice in DPBS, counted in a hemocytometer and cell viability determined by trypan blue exclusion ( $>94 \%$ for all experiments). $1.5 \times 10^{5}$ cells/well were seeded in triplicate in 96-well U-bottom plates (Corning Costar Inc., Corning, NY), in a final volume of $200 \mu \mathrm{l} /$ well of RPMI-1640 supplemented with $100 \mathrm{U} / \mathrm{ml}$ of penicillin, $100 \mu \mathrm{g} / \mathrm{ml}$ of streptomycin, and $10 \%$ human pooled serum (PHS). Cells were cultured in the presence or absence of $5 \mu \mathrm{g} / \mathrm{ml}$ (final concentration) of PPD, the fusion protein E6-C10, or the selected DosR and Rpf antigens. Cell cultures were incubated at $37{ }^{\circ} \mathrm{C}, 5 \%$ de $\mathrm{CO} 2$, and $90 \%$ relative humidity for $168 \mathrm{~h}$ (7-days). Dead cells were determined by staining with 7AAD (Thermo Fisher Scientific, Carlsbad, CA). The number of viable cells at the end of the culture period was $>80 \%$ for all experiments.

\section{IFNY quantitation}

Quantitation of IFNY present in the supernatants of non-stimulated and antigen-stimulated PBMCs was performed by the Luminex technology using a commercial kit from Millipore (Millipore, Billerica, MA, USA), and a Luminex reader (Bioplex 200 Analyzer, BioRad, Laboratories Inc), as previously reported [29].

\section{Statistical analysis}

The IFN $\gamma$ levels in response to antigens were expressed as net values. The Shapiro-Wilk test was used to test normality in data distribution. The difference in the IFN $\gamma$ levels between LTBI and PTB was determined by the nonparametric U-Mann Whitney test. The differences in gender and BCG scar between LTBI and PTB was tested by the Chi-square statistics. The capacity of IFN $\gamma$ levels to discriminate between LTBI and PTB was tested using Receiver Operating Characteristics (ROC) curves. The cut-off level of IFNy that determines the highest sensitivity and specificity for each of the antigens was identified by the Youden index (calculated using the formula: sensitivity + specificity - 1) [41]. The cut-off levels were used to categorize the high and low responses to IFN $\gamma$ to each one of the antigens, and later to determine the antigens predictive capacity for disease status (LTBI and PTB). For this purpose, multivariate approaches were used. The multiple correspondence analysis (MCA) was used to determine the response profiles to each antigen based on disease status while the $\mathrm{CHi}$-squared Automatic Interaction Detection (CHAID) [42], was used to determine the antigens that better influence the prediction of being LTBI or PTB. To quantify the degree of association and the influence of the IFN $\gamma$ response levels of each antigen on the disease status, a logistic regression model was built using a 25 LTBI and PTB subsample that was further validated with a 16 LTBI and PTB subsample. For model estimation, the Bootstrapping method with 100 repetitions was used including the first subsample and all antigens. For model validation, the coefficients obtained with the first 25 subsample (16 LTBI and 9 PTB) were used, and the calibration was evaluated by using the percentage of correct classification (87.5\%), the Kappa statistic (0.75 C195\%: 0.42-1.0), and the AUC (Area Under the Curve, 0,94 (IC95\%: 0,83-1,0) with its respective confidence interval. The Forward method was also explored to get 
information on the top antigens to predict active disease. Statistical analyses were performed using the Statistic Package for Social Science Program (SPSS version 21.0, Chicago, IL, USA). Statistical differences $\leq 0.05$ were considered significant.

\section{Results}

\section{Demographic data}

The median age of the LTBI group was 38.5-years old (IQR $=26.75-52.75)$, $55 \%$ males, and $80 \%$ had a visible BCGscar. The group of individuals with active pulmonary TB (PTB) had a median age of 28 -years old (IQR $=24-41)$, and $71 \%$ were BCG-scar positive. No significant differences in age, gender or BCG-scar positivity were observed between both groups of individuals (data not shown).

\section{Capacity of the individual antigens to discriminate between LTBI and PTB disease status}

The utilization of RD-1 antigens of $M t b$ in the commercially available IGRAs has contributed to a higher specificity for infection detection in comparison to the tuberculin skin test. Similar to the TST, however, IGRAs cannot discriminate between LTBI and active TB [4345]. Therefore, the identification of new (host and/or pathogen) biomarkers that discriminate between latent and active TB is a necessity [3]. Thus, we determined the in vitro production of IFN $\gamma$ by PBMCs from LTBI and PTB in response to selected Mtb DosR (Rv1737c, Rv2029c and Rv2628) and Rpf (Rv0867c and Rv2389c) antigens [29, 30, 33] using 7-day PMBC stimulation assay. LTBI individuals displayed significantly higher levels of IFN $\gamma$ in response to PPD $(p=0.004), \mathrm{E} 6-\mathrm{C} 10(p$ $<0.001), \quad \operatorname{Rv} 1737 \mathrm{c} \quad(p=0.004), \quad \operatorname{Rv} 2029 \mathrm{c} \quad(p<0.001)$, $\operatorname{Rv} 2628(p=0.017), \operatorname{RpfA}(p=0.009)$ and $\operatorname{RpfD}(p=$ 0.013) (Fig. 1; Table 1 and Additional file 1: Table S1).

Then, ROC curves were used to evaluate the capacity of the antigen specifically induced IFN $\gamma$ levels to classify LTBI from PTB individuals and to determine the optimal cutoff for each antigen. ROC curves showed that IFNY production in response to the studied antigens allowed to differentiate LTBI from PTB with areas under the curve (AUC) higher than 0.70;

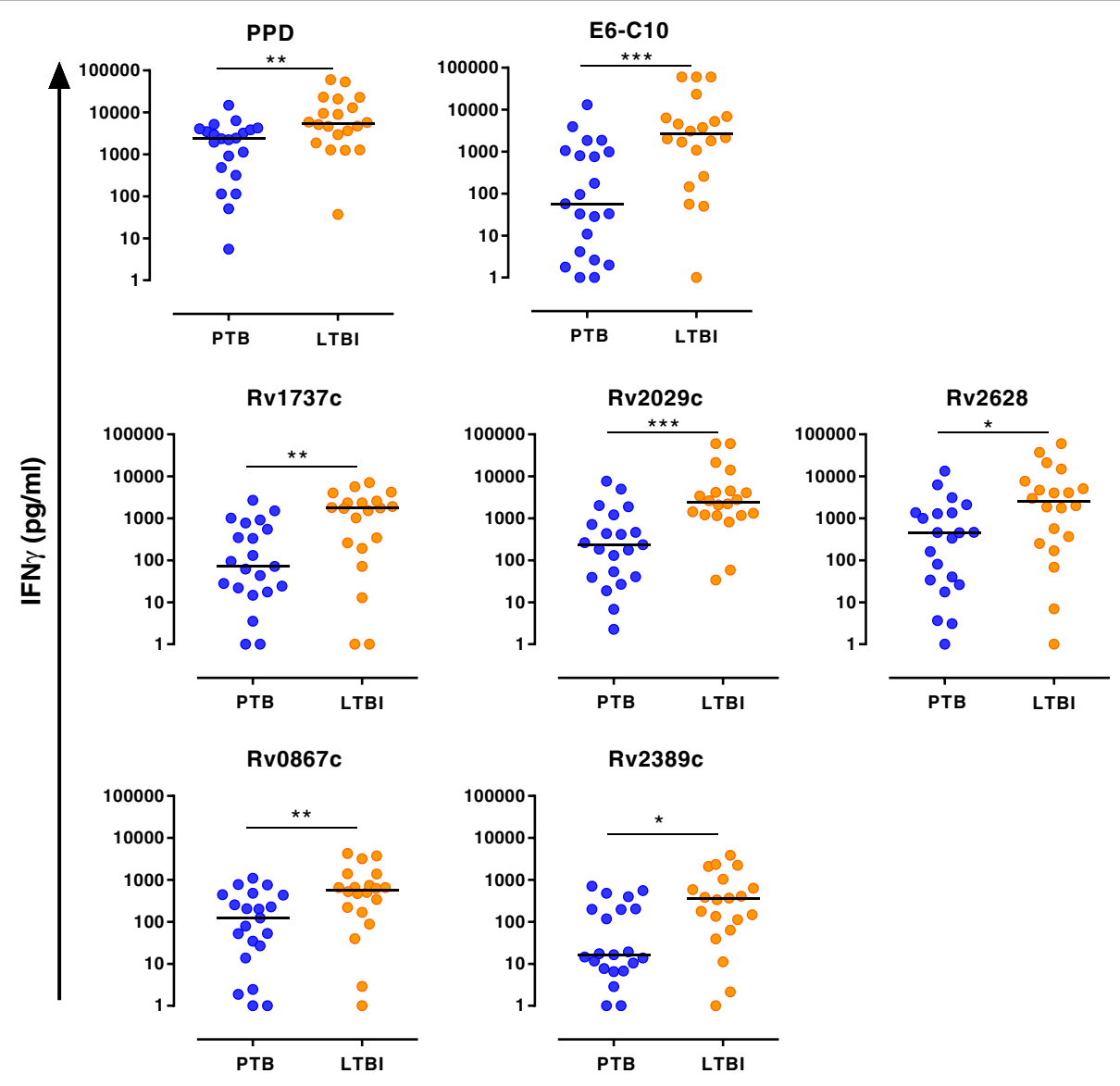

Fig. 1 Comparison of the IFNY levels in LTBI and PTB in response to RD-1 Esat6-Cfp10 (E6-C10), DosR and Rpf antigens. PBMCS $\left(1 \times 10^{5}\right)$ were cultured for 7 days, in the presence or absence of PPD, E6-C10 and the DosR and Rpf antigens. IFNy levels in LTBI (orange circles) and PTB (blue circles) were determined by Luminex. Mann-Whitney U-test was used to calculate statistical differences between groups and $p$-values are shown in the $\operatorname{graphs}(*, p<0.05 ; * *, p<0.01 ; * *, p<0.001)$ 
Table 1 Abilities of the IFNy in response to PPD, E6-C10, DosR and Rpf antigens to discriminate between LTBI and PTB

\begin{tabular}{|c|c|c|c|c|c|c|c|}
\hline Antigens & PTB Median (IQR) & HHC-LTBI Median (IQR) & $p$-value* & AUC (95\% Cl) & Cut-off (pg/ml) & Sensitivity (\%) & Specificity (\%) \\
\hline \multicolumn{8}{|l|}{ DosR } \\
\hline Rv1737c & $70.7(18.8-664.2)$ & $1742.0(209.2-2528.0)$ & 0.0041 & $0.76(0.60-0.92)$ & 1014.96 & 65.0 & 90.5 \\
\hline Rv2029c & 233.4 (38.9-961.3) & $2421.0(1182.0-4426.0)$ & 0.0003 & $0.82(0.69-0.96)$ & 763.15 & 90.0 & 76.2 \\
\hline Rv2628 & $452.3(29.1-1363.0)$ & $2489.0(281.0-7006.0)$ & 0.0173 & $0.72(0.55-0.88)$ & 1569.41 & 65.0 & 81.0 \\
\hline \multicolumn{8}{|l|}{ Rpf } \\
\hline Rv0867c & $121.8(19.3-437.2)$ & $576.8(181.0-1224.0)$ & 0.0091 & $0.74(0.58-0.89)$ & 454.89 & 65.0 & 81.0 \\
\hline Rv2389c & $15.5(6.3-200.3)$ & 349.5 (74.72-932.6) & 0.0126 & $0.73(0.57-0.89)$ & 28.36 & 85.0 & 61.9 \\
\hline \multicolumn{8}{|l|}{ Control } \\
\hline E6-C10 & $56.5(2.4-1027.0)$ & $2623.0(461.0-6761.0)$ & 0.0006 & $0.80(0.66-0.94)$ & 1070.36 & 75.0 & 81.0 \\
\hline PPD & 2355.0 (401.3-3949.0) & $5453.0(2137.0-18,874.0)$ & 0.0042 & $0.76(0.60-0.91)$ & 4464.11 & 65.0 & 86.0 \\
\hline
\end{tabular}

IQR Interquartile Range. AUC Area Under the ROC Curve. CI Confidence Interval

* $p$-value for the Mann-Whitney test

moreover, from the analyses the Rv2029c antigen was found to have the highest contribution to the higher discrimination (Table 1).

\section{Utility of antigens combinations to discriminate between LTBI and PTB}

To fully evaluate how the IFN $\gamma$ response to all antigens could improve the discriminatory capacity between LTBI and PTB, we used multiple correspondence analysis (MCA), a technique for nominal categorical data used to detect and represent underlying structures in a dataset [46]. The MCA results revealed that LTBI individuals are associated with a profile characterized by higher levels of IFN $\gamma$ in response to the different antigens while PTB are associated with a lower IFN $\gamma$ profile (Fig. 2).

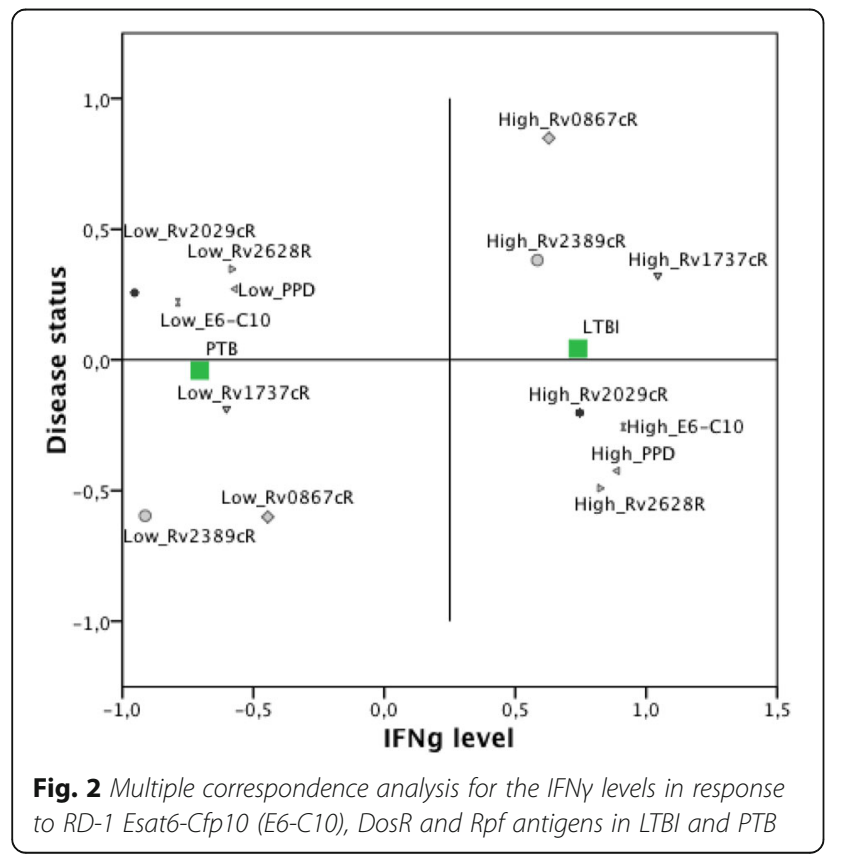

To identify the variable that better predict the disease status (LTBI or PTB), we performed an analysis based on decision trees (CHAID), to determine which antigens better influence the prediction of being LTBI or PTB. This analysis showed that the higher IFN $\gamma$ levels produced in response to the DosR antigen Rv2029c (PfkB), is the antigen that best predicted disease status (Fig. 3). The individuals that presented with higher levels of IFNY in response to Rv2029c display a higher probability of being latently infected (78.3\%; Node 1, Fig. 3), while individuals that produced low levels of IFNY in response to Rv2029c displayed a higher probability of being PTB (88.9\%; Node 2, Fig. 3). Also, this method correctly classified $82.9 \%$ of the individuals.

To confirm the single antigen that best differentiates between PTB and LTBI, we used the Forward selection method of stepwise regression. The results (data not shown), confirmed Rv2029c as the antigen that best discriminates between those two conditions. Moreover, employing a cross-validation strategy as described in the Statistical Analyses section, this analysis showed that a combination of four antigens E6-C10, Rv2029c, Rv0867c, and Rv2389c, are those that provide the greatest discrimination between LTBI and PTB (Table 2). Using this model, it was possible to construct a prediction rule allowing separation of latent from active TB (Classification score: $-2,35+(0,42 \times \mathrm{PPD})+(1,90 \times \mathrm{E} 6 \mathrm{C} 10 \mathrm{R})+(0,48$ x $\quad$ Rv1737cR $)+(2,45 \quad x \quad$ Rv2029cR $)+(0,138 \quad x$ Rv2628R $)+(1,86$ x Rv0867cR $)-(1,87$ x Rv2389cR $)$ Probability of LTB: $1(1+\mathrm{e}$-classification score $))$. The validation of this model in a sub-sample $(n=16)$, showed a high capacity to differentiate LTBI from PTB with an $\mathrm{AUC}=0,94$ (95\% CI:0.83-1.0). Additionally, this model correctly classified $85,7 \%$ of the LTBI and $88,9 \%$ of the PTB. 


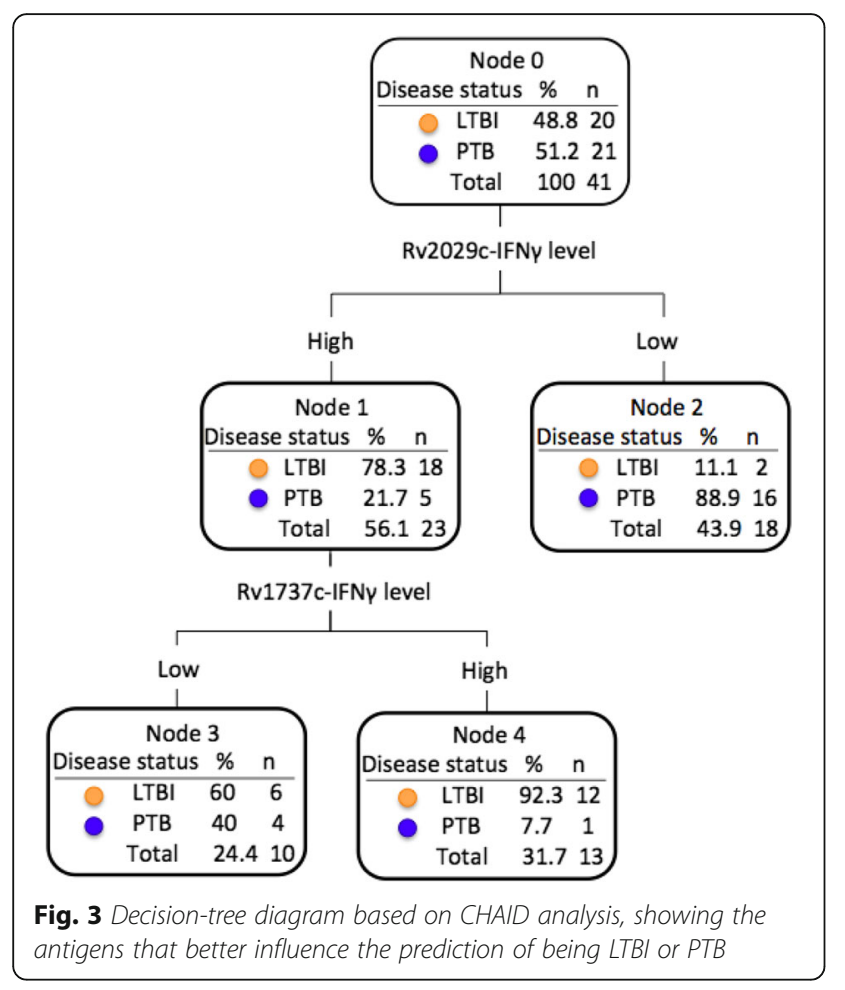

\section{Discussion}

The immune response to PPD and IGRA antigens has a low power to discriminate between LTBI and PTB $[44,45]$. Indeed, the predictive value of IGRAs for progression to TB disease is low and slightly but not significantly higher than that of the TST $[9,45]$. Therefore, new biomarkers are urgently needed to facilitate the diagnosis of LTBI [3].

Herein we have evaluated the potential of the $M t b$ antigens E6-C10, the DosR Rv1737c, Rv2029c, and Rv2628, and the Rpf RpfA and RpfD to discriminate latent TB

Table 2 Capacity of PPD, E6C10, DosR and Rpf antigens to discriminate between $\mathrm{LTBI}$ and PTB

\begin{tabular}{|c|c|c|c|c|c|c|}
\hline \multicolumn{7}{|l|}{ Model } \\
\hline & & \multirow[t]{3}{*}{$B$} & \multicolumn{4}{|c|}{ Bootstrap $^{a}$} \\
\hline & & & \multirow[t]{2}{*}{ SE } & \multirow{2}{*}{$\begin{array}{l}\text { Sig. } \\
\text { (bilateral) }\end{array}$} & \multicolumn{2}{|l|}{$\mathrm{Cl}(95 \%)$} \\
\hline & & & & & Inferior & Superior \\
\hline \multirow[t]{8}{*}{ Step 1} & PPD & 0.424 & $34.863^{b}$ & $0.139^{b}$ & -42.725 & 76.794 \\
\hline & E6C10 & 1.899 & $43.275^{b}$ & $0.025^{b}$ & -62.260 & 119.469 \\
\hline & Rv1737c & 0.478 & $30.405^{b}$ & $0.152^{b}$ & -41.714 & 76.074 \\
\hline & Rv2029c & 2.454 & $40.806^{b}$ & $0.038^{b}$ & -39.811 & 151.793 \\
\hline & Rv2628 & 0.138 & $32.905^{b}$ & $0.253^{b}$ & -77.272 & 41.945 \\
\hline & Rv0867c & 1.860 & $35.250^{b}$ & $0.025^{b}$ & -36.482 & 107.89 \\
\hline & Rv2389c & -1.865 & $39.777^{b}$ & $0.025^{b}$ & -132.135 & 73.181 \\
\hline & Constant & -2.354 & $31.571^{b}$ & $0.127^{b}$ & -95.683 & -0.056 \\
\hline
\end{tabular}

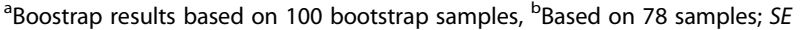
Standard Error, $\mathrm{Cl}$ Confidence Interval, Sig Significance infection from active TB. The DosR antigens evaluated in the present study induced a higher production of IFN $\gamma$ in stimulated PBMCs from LTBI compared to PTB. Also, the production of IFNY to DosR antigens showed a high probability to discriminate disease status (AUC >0.70). Different studies, including ours, indicate that LTBI preferentially recognizes DosR antigens compared to PTB in different human populations [24$26,29,30,32,33,35,37]$. In this study, Rv2029c (pfkB) was included in the model that better-predicted disease status, with a correct classification of $78.3 \%$ of LTBI and $88.9 \%$ of PTB, according to the analysis based on decision trees (CHAID). Additionally, the logistic regression analysis using the forward method also showed Rv2029c as the antigen that better discriminates between those two conditions (data not shown).

Recent studies have highlighted the immunological importance to Rv2029c. Vaccination of mice with DosR antigens, including Rv2029c induced strong humoral and/or cellular Th1-type (interleukin-2 and gamma interferon) immune responses [47]. In humans, a stronger response to Rv2029c in LTBI compared to PTB has been reported in the Netherlands [24], Africa [25, 35], Japan [26], China [36], Brazil [27], and Colombia [29, 30, 33]. Remarkably, in a one-year longitudinal study in Brazilian subjects recently exposed to TB, classified by IGRA and TST positivity, PBMCs stimulation with latency antigens, including Rv2029c, it was found that combining the IFNY responders to Rv2029c, Rv2031c plus Rv2034 detected 90.3\% of IGRA$\mathrm{RD} 1(+)$ and $66.7 \%$ of $\mathrm{TST}(+)$ contacts, while $95 \%$ were identified by classifying them as TST(+) IGRA-RD(+) and $11 \%$ as TST(-) IGRA(-). Moreover, in the follow-up, the TST converters also demonstrated an IFN $\gamma$ conversion to Rv2029c and Rv2031c, whereas the only TB incident case was detected via IGRA-Rv2029c and TST previous to developing TB [25]. In another study, the LTBI diagnostic performance of Rv2029c was higher than Rv2628 and Rv1813c by ROC evaluation [36]. Furthermore, in a study in of the in vitro immune response to the DosR antigens Rv1733c, Rv2029c, Rv2628 before and after 2-week anti-tuberculosis treatment in Ghanaians PTB, it was found that the second week of effective chemotherapy was characterized by a general increase in cytokine response to $M t b$-specific antigens suggesting improvement in cellular response to therapy [48]. Thus, our studies strengthen the observation that Rv2029c may constitute a relevant biomarker of LTBI. Besides, our findings that Rv2029 was included in the model of logistic regression analysis that best predicted latent and active TB, along with E6-C10 and Rpf antigens, may suggest that Rv2029c is a useful diagnostic candidate who might increase the capacity to discriminate between LTBI and PTB in combination with antigens currently used as such as ESAT-6 and CFP-10, even though much larger studies need to be performed to validate the present results. 
Similar to the DosR antigens, the Rpf antigens (RpfA and $\mathrm{RpfD}$ ) induced a higher production of IFN $\gamma$ in stimulated PBMCs from LTBI compared to PTB and showed a high probability to discriminate disease status (AUC $>0.70$ ). Additionally, these antigens were included in the model that predicted the disease status. The results obtained in this study are consistent with those reported by Chegou and colleagues [49], who found that Rv0867c (RpfA) and Rv2389c (RpfD) were included in antigen combinations discriminating between HHC and PTB. It has been reported that rpf genes are differentially expressed at different growth stages, and stress conditions, with $r p f A$ and $r p f D$, mainly expressed during early resuscitation [50]. Studies conducted in different human population, including ours, indicate that an immune response to RpfA and RpfD antigens has been preferentially found in LTBI suggesting that the immune response to $\mathrm{Rpf}$ antigens may play a protective role against bacilli reactivation $[29,34,35]$. It has been suggested that the bacilli may indeed still be replicating but are controlled by the host immune response during LTBI infection [51, 52]. So, the host may be exposed to antigens from the different metabolic states of $M t b$ in vivo, and the response to these antigens may be detected in in-vitro stimulation assays. Thus, our results suggest that RpfA and RpD antigens also could be added to current diagnostic tests to improve the capacity to discriminate between LTBI and PTB.

On the other hand, and somewhat unexpectedly, our results show that the fusion protein E6-C10 induced a higher production of IFN $\gamma$ in stimulated PBMCs from LTBI compared to PTB and that the production of IFN $\gamma$ to E6-C10 antigens showed a high probability to differentiate between LTBI and PTB (AUC >0.70). Although E6-C10 was not selected as the best predictor of the disease status, according to the analysis based on decision trees (CHAID) and the logistic regression analysis using the forward method, E6-C10 was included in the model that better discriminates between LTBI and PTB. This result is consistent with those reported by Chegou and colleagues [49], who found that E6-C10 was included in the most of the antigen combinations discriminating between presence and absence of TB disease. ESAT- 6 and CFP-10 antigens are encoded by genes located within the region of difference 1 (RD1) of the $M t b$ genome, a chromosomal segment absent in the BCG vaccine strains and most of the NTM $[7,8]$. So, the utilization of these antigens in the commercially available IGRAs has contributed to a higher specificity for infection detection in comparison to the tuberculin skin test $[44,45]$. The RD1 antigens are described to be secreted during $M t b$ active replication $[6,53]$. Additionally, it has been described that the expression of genes encoding early stage proteins such as ESAT-6 is repressed during the stationary phase of $M t b$ growth in the lungs of chronically infected mice [54], suggesting that they might not be expressed optimally during later stages of $M t b$ infection and likely play a much less dominant role during LTBI than proteins from the DosR regulón or Rpf antigens. Collectively these results suggest that the use the DosR antigen Rv2029c and RpfA and Rpf in $\mathrm{T}$ cell assays (IGRAs), in addition to E6-C10, could enhance the ability to differentiate LTBI from TB disease especially in a high-burden setting where a mixture of recent and old infections is commonly found [38].

Our study presents some limitations such as the small sample size which therefore should be extended and validated in a more significant number of participants and different human populations; the use of a 7-day in vitro culture assay rather than a more user friendly assay; the absence of a healthy control group; and the lack of longitudinal evaluation of progression to disease. Although a recent infection is more detectable in a short-term stimulation, it has been argued that long-term stimulation is more sensitive to the detection of LTBI than those with short-term stimulation times particularly in regions of high endemicity in which a mixture of recent and old infections are frequently found $[32,55,56]$. Thus, longterm stimulation may be better to measure central memory T-cell responses [55-57]. By using long-term stimulation conditions, our group has previously reported the enhanced ability to detect Tcm cells $\left(\mathrm{CD} 45 \mathrm{RO}^{+} \mathrm{CD} 27^{+}\right)$in response to mycobacterial antigens $[29,30,58,59]$. For that reason, we used longterm cultures to define the LTBI status and compared the immune response between the study groups. As previously pointed out, future works should include a prospective evaluation the antigens and host markers identified in this study, using larger sample size, different geographic settings and using preferably shortterm assays to detect effector cell responses. Future studies should also evaluate the antigens and host markers in different study populations as such as children, individuals with immune suppression (e.g., due to HIV coinfection, therapy with TNF- $\alpha$ inhibitors, or due to type 2 diabetes), in TB patients after anti-TB therapy, in patients with extrapulmonary TB, and also in individuals with other lung diseases [49].

\section{Conclusions}

We found that in an endemic community for TB of the city of Medellín, Colombia, human PBMC responses to E6-C10, the Mtb DosR antigens Rv2029c (PFKB) and the Rpf antigens, RpfA and RpfD, can discriminate latent from active $\mathrm{TB}$, and may be potential candidates for improved diagnostic tests as well as anti-tuberculous vaccines. 


\section{Additional file}

Additional file 1: Table S1. Raw IFNy levels in PTB and LTBI individuals in response to PPD, RD1 Esat6-Cfp10 (E6-C10), DosR and Rpf antigens. PBMCs $\left(1 \times 10^{5}\right)$ were cultured for seven days, in presence or absence of PPD, E6-C10, and the DosR and Rpf antigens ( $5 \mu \mathrm{g} / \mathrm{ml})$. Levels of IFNy in the supernatants were determined by Luminex. Net values were obtained by subtracting the background values (non-stimulated cells) and are shown in the Table. (DOCX $60 \mathrm{~kb}$ )

\section{Abbreviations}

AUC: Area under the curve; BCG: Bacillus Calmette-Guérin; Cfp10: Culture filtrate Protein; CHAID: CHi-squared Automatic Interaction Detection; Cl: Confidence intervals; Esat-6: 6 kDa early secretory antigenic target; IFNg: Interferon gamma; IGRA: Interferon gamma release assay; LTBI: Latent tuberculosis infection; MDA: Multiple correspondence analysis; Mtb: Mycobacterium tuberculosis; narK2: nitrate/nitrite transporter NarK2; NTM: Non-tuberculous mycobacterium; PBMCs: Peripheral blood mononuclear cells; pfkB: Phosphofructokinase B; PPD: Purified Protein derivative; PRISMA: Preferred reporting items for systematic reviews and meta-analyses; PTB: Pulmonary tuberculosis; RNIs: Reactive nitrogen intermediates; ROC: Receiver operating curve; ROIs: Reactive oxygen intermediates; Rpf: Resuscitation promoting factor; TB: Tuberculosis; TST: Tuberculin skin test

\section{Acknowledgements}

We acknowledge the TB patients and latently infected individuals who consented to participate in this study.

\section{Funding}

This work was funded by Colciencias, Bogotá, Colombia (1115-459-21461), Comité para el Desarrollo de la Investigacion (CODI) (01554), Programa Sostenibilidad Universidad de Antioquia 2014-2015 (01554) (LFB), and EC FP7 NEWTBVAC (HEALTH.F3.2009 241745), EC HORIZON2020 TBVAC2020 (643381), EC FP7 VACTRAIN (FP7-INFRA-2012-312661) (THMO)

\section{Availability of data and materials}

All data generated or analyzed during this study are included in this published article and its supplementary (Additional file 1: Table S1) information files.

\section{Authors' contributions}

LA, experimental procedures, analysis and interpretation of data and writing the paper; DM, statistical analysis and critically reviewing the manuscript; $\mathrm{KLMF}$, critically reviewing the manuscript; $T H M O$, analysis and interpretation of data, and critically reviewing the manuscript; LFB, conception and design of the study, analysis and interpretation of data, and manuscript writing and as a PI. All authors have read and approved the final manuscript.

\section{Ethics approval and consent to participate}

TB patients and LTBI individuals signed an informed consent previously approved by the Ethics Committee of the Instituto de Investigaciones Médicas of the Facultad de Medicina, Universidad de Antioquia, Medellín, Colombia.

\section{Consent for publication}

Not applicable.

\section{Competing interests}

The authors declare that they have no competing interests.

\section{Publisher's Note}

Springer Nature remains neutral with regard to jurisdictional claims in published maps and institutional affiliations.

\section{Author details}

'Grupo de Inmunología Celular e Inmunogenética (GICIG), Albinusdreef 2 2333 Leiden, ZA, Netherlands. ${ }^{2}$ Universidad Pontificia Bolivariana (UPB), Albinusdreef 2, 2333 Leiden, ZA, Netherlands. ${ }^{3}$ Department of Infectious Diseases, Leiden University Medical Centre, Albinusdreef 2, 2333 Leiden, ZA Netherlands. ${ }^{4}$ Instituto de Investigaciones Médicas, Facultad de Medicina, Universidad de Antioquia, UdeA, Calle 70 No. 52-21, Medellín, Colombia.
Received: 26 April 2017 Accepted: 17 December 2017

Published online: 08 January 2018

\section{References}

1. WHO: Global tuberculosis report (WHO/HTM/TB/2016.13): World Health Organization. 2016.

2. Dye C, Scheele S, Dolin P, Pathania V, Raviglione MC. Consensus statement. Global burden of tuberculosis: estimated incidence, prevalence, and mortality by country. WHO global surveillance and monitoring project. JAMA. 1999;282(7):677-86.

3. Esmail H, Barry CE 3rd, Wilkinson RJ. Understanding latent tuberculosis: the key to improved diagnostic and novel treatment strategies. Drug Discov Today. 2012;17(9-10):514-21.

4. Farhat M, Greenaway C, Pai M, Menzies D. False-positive tuberculin skin tests: what is the absolute effect of BCG and non-tuberculous mycobacteria? Int J Tuberc Lung Dis. 2006;10(11):1192-204.

5. Andersen P, Munk ME, Pollock JM, Doherty TM. Specific immune-based diagnosis of tuberculosis. Lancet. 2000;356(9235):1099-104

6. Andersen P, Doherty TM, Pai M, Weldingh K. The prognosis of latent tuberculosis: can disease be predicted? Trends Mol Med. 2007:13(5):175-82.

7. Mahairas GG, Sabo PJ, Hickey MJ, Singh DC, Stover CK. Molecular analysis of genetic differences between Mycobacterium Bovis BCG and virulent M. Bovis. J Bacteriol. 1996;178(5):1274-82.

8. Behr MA, Wilson MA, Gill WP, Salamon H, Schoolnik GK, Rane S, Small PM. Comparative genomics of BCG vaccines by whole-genome DNA microarray. Science. 1999:284(5419):1520-3.

9. Rangaka MX, Wilkinson KA, Glynn JR, Ling D, Menzies D, MwansaKambafwile J, Fielding K, Wilkinson RJ, Pai M. Predictive value of interferongamma release assays for incident active tuberculosis: a systematic review and meta-analysis. Lancet Infect Dis. 2012;12(1):45-55.

10. Petruccioli E, Scriba TJ, Petrone L, Hatherill M, Cirillo DM, Joosten SA, Ottenhoff TH, Denkinger CM, Goletti D. Correlates of tuberculosis risk: predictive biomarkers for progression to active tuberculosis. Eur Respir J. 2016;48(6):1751-63.

11. Voskuil MI, Schnappinger D, Visconti KC, Harrell MI, Dolganov GM Sherman DR, Schoolnik GK. Inhibition of respiration by nitric oxide induces a mycobacterium tuberculosis dormancy program. J Exp Med. 2003;198(5):705-13.

12. Schnappinger D, Ehrt S, Voskuil MI, Liu Y, Mangan JA, Monahan IM, Dolganov G, Efron B, Butcher PD, Nathan C, et al. Transcriptional adaptation of mycobacterium tuberculosis within macrophages: insights into the Phagosomal environment. J Exp Med. 2003;198(5):693-704.

13. Sherman DR, Voskuil M, Schnappinger D, Liao R, Harrell MI, Schoolnik GK. Regulation of the mycobacterium tuberculosis hypoxic response gene encoding alpha -crystallin. Proc Natl Acad Sci U S A. 2001;98(13):7534-9.

14. Betts JC, Lukey PT, Robb LC, McAdam RA, Duncan K. Evaluation of a nutrient starvation model of mycobacterium tuberculosis persistence by gene and protein expression profiling. Mol Microbiol. 2002:43(3):717-31.

15. Ehlers S, Schaible UE. The granuloma in tuberculosis: dynamics of a hostpathogen collusion. Front Immunol. 2012;3:411.

16. Lenaerts A, Barry CE 3rd, Dartois V. Heterogeneity in tuberculosis pathology, microenvironments and therapeutic responses. Immunol Rev. 2015;264(1):288-307.

17. Park HD, Guinn KM, Harrell MI, Liao R, Voskuil MI, Tompa M, Schoolnik GK, Sherman DR. Rv3133c/dosR is a transcription factor that mediates the hypoxic response of mycobacterium tuberculosis. Mol Microbiol. 2003;48(3):833-43.

18. Mukamolova GV, Turapov OA, Young DI, Kaprelyants AS, Kell DB, Young M A family of autocrine growth factors in mycobacterium tuberculosis. Mol Microbiol. 2002:46(3):623-35

19. Shleeva MO, Bagramyan K, Telkov MV, Mukamolova GV, Young M, Kell DB, Kaprelyants AS. Formation and resuscitation of "non-culturable" cells of Rhodococcus rhodochrous and mycobacterium tuberculosis in prolonged stationary phase. Microbiology. 2002;148(Pt 5):1581-91.

20. Downing KJ, Mischenko W, Shleeva MO, Young DI, Young M, Kaprelyants AS, Apt AS, Mizrahi V. Mutants of mycobacterium tuberculosis lacking three of the five rpf-like genes are defective for growth in vivo and for resuscitation in vitro. Infect Immun. 2005:73(5):3038-43.

21. Kana BD, Gordhan BG, Downing KJ, Sung N, Vostroktunova G, Machowski EE, Tsenova L, Young M, Kaprelyants A, Kaplan G, et al. The resuscitationpromoting factors of mycobacterium tuberculosis are required for virulence and resuscitation from dormancy but are collectively dispensable for growth in vitro. Mol Microbiol. 2008;67(3):672-84. 
22. Mukamolova GV, Turapov O, Malkin J, Woltmann G, Barer MR. Resuscitationpromoting factors reveal an occult population of tubercle bacilli in sputum. Am J Respir Crit Care Med. 2010;181(2):174-80.

23. Huang W, Qi Y, Diao Y, Yang F, Zha X, Ren C, Huang D, Franken KL, Ottenhoff $\mathrm{TH}, \mathrm{Wu} \mathrm{Q}$, et al. Use of resuscitation-promoting factor proteins improves the sensitivity of culture-based tuberculosis testing in special samples. Am J Respir Crit Care Med. 2014;189(5):612-4

24. Leyten $\mathrm{EM}$, Lin MY, Franken $\mathrm{KL}$, Friggen $\mathrm{AH}$, Prins $\mathrm{C}$, van Meijgaarden $\mathrm{KE}$, Voskuil MI, Weldingh K, Andersen P, Schoolnik GK, et al. Human T-cell responses to 25 novel antigens encoded by genes of the dormancy regulon of mycobacterium tuberculosis. Microbes Infect. 2006;8(8):2052-60

25. Black GF, Thiel BA, Ota MO, Parida SK, Adegbola R, Boom WH, Dockrell HM, Franken KL, Friggen AH, Hill PC, et al. Immunogenicity of novel DosR regulonencoded candidate antigens of mycobacterium tuberculosis in three highburden populations in Africa. Clin Vaccine Immunol. 2009;16(8):1203-12.

26. Hozumi H, Tsujimura K, Yamamura Y, Seto S, Uchijima M, Nagata T, Miwa S, Hayakawa H, Fujisawa T, Hashimoto D, et al. Immunogenicity of dormancyrelated antigens in individuals infected with mycobacterium tuberculosis in Japan. Int J Tuberc Lung Dis. 2013;17(6):818-24.

27. Araujo LS, da Silva NB, da Silva RJ, Leung JA, Mello FC, Saad MH. Profile of interferon-gamma response to latency-associated and novel in vivo expressed antigens in a cohort of subjects recently exposed to mycobacterium tuberculosis. Tuberculosis (Edinb). 2015;95(6):751-7.

28. Pena D, Rovetta Al, Hernandez Del Pino RE, Amiano NO, Pasquinelli V, Pellegrini JM, Tateosian NL, Rolandelli A, Gutierrez M, Musella RM, et al. A mycobacterium tuberculosis dormancy antigen differentiates latently infected bacillus Calmette-Guerin-vaccinated individuals. EBioMedicine. 2015;2(8):882-8.

29. Riano F, Arroyo L, Paris S, Rojas M, Friggen AH, van Meijgaarden KE, Franken KL, Ottenhoff TH, Garcia LF, Barrera LF. T cell responses to DosR and Rpf proteins in actively and latently infected individuals from Colombia. Tuberculosis (Edinb). 2012;92(2):148-59.

30. Arroyo L, Rojas M, Ortiz BL, Franken KL, Garcia LF, Ottenhoff TH, Barrera LF. Dynamics of the $T$ cell response to mycobacterium tuberculosis DosR and Rpf antigens in a Colombian population of household contacts of recently diagnosed pulmonary tuberculosis patients. Tuberculosis (Edinb). 2016:97:97-107.

31. Commandeur S, Lin MY, van Meijgaarden KE, Friggen AH, Franken $K L$, Drijfhout JW, Korsvold GE, Oftung F, Geluk A, Ottenhoff TH. Double- and monofunctional CD4(+) and CD8(+) T-cell responses to mycobacterium tuberculosis DosR antigens and peptides in long-term latently infected individuals. Eur J Immunol. 2011;41(10):2925-36.

32. Goletti D, Butera O, Vanini V, Lauria FN, Lange C, Franken KL, Angeletti C, Ottenhoff TH, Girardi E. Response to Rv2628 latency antigen associates with cured tuberculosis and remote infection. Eur Respir J. 2010;36(1):135-42.

33. Arroyo L, Rojas M, Franken $\mathrm{KL}$, Ottenhoff TH, Barrera LF. Multifunctional $T$ cell response to DosR and Rpf antigens is associated with protection in long-term mycobacterium tuberculosis-infected individuals in Colombia. Clin Vaccine Immunol. 2016;23(10):813-24.

34. Huang W, Qi Y, Ren C, Wen H, Franken KL, Ottenhoff TH, Shen J. Interferongamma responses to mycobacterium tuberculosis Rpf proteins in contact investigation. Tuberculosis (Edinb). 2013;93(6):612-7.

35. Sutherland JS, Lalor MK, Black GF, Ambrose LR, Loxton AG, Chegou NN, Kassa D, Mihret A, Howe R, Mayanja-Kizza $H$, et al. Analysis of host responses to mycobacterium tuberculosis antigens in a multi-site study of subjects with different TB and HIV infection states in sub-Saharan Africa. PLoS One. 2013;8(9):e74080.

36. Bai XJ, Liang Y, Yang YR, Feng JD, Luo ZP, Zhang JX, Wu XQ. Potential novel markers to discriminate between active and latent tuberculosis infection in Chinese individuals. Comp Immunol Microbiol Infect Dis. 2016;44:8-13.

37. Rakshit S, Adiga V, Nayak S, Sahoo PN, Sharma PK, van Meijgaarden KE, UJA UJ, Dhar C, Souza GD, Finak G, et al. Circulating mycobacterium tuberculosis DosR latency antigen-specific, polyfunctional, regulatory IL10+ Th17 CD4 Tcells differentiate latent from active tuberculosis. Sci Rep. 2017;7(1):11948.

38. del Corral H, Paris SC, Marin ND, Marin DM, Lopez L, Henao HM, Martinez T, Villa L, Barrera LF, Ortiz BL, et al. IFNgamma response to mycobacterium tuberculosis, risk of infection and disease in household contacts of tuberculosis patients in Colombia. PLoS One. 2009;4(12):e8257.

39. Lin MY, Geluk A, Smith SG, Stewart AL, Friggen AH, Franken KL, Verduyn MJ, van Meijgaarden KE, Voskuil MI, Dockrell HM, et al. Lack of immune responses to mycobacterium tuberculosis DosR regulon proteins following Mycobacterium Bovis BCG vaccination. Infect Immun. 2007;75(7):3523-30.
40. Franken $\mathrm{KL}$, Hiemstra HS, van Meijgaarden KE, Subronto Y, den Hartigh J, Ottenhoff TH, Drijfhout JW. Purification of his-tagged proteins by immobilized chelate affinity chromatography: the benefits from the use of organic solvent. Protein Expr Purif. 2000;18(1):95-9.

41. Cerda J, Cifuentes L. Using ROC curves in clinical investigation: theoretical and practical issues. Rev Chil Infectol. 2012;29(2):138-41.

42. Kass GV. An exploratory technique for investigating large quantities of categorical data. Appl Stat. 1980;29:119-27.

43. Pai M, Dheda K, Cunningham J, Scano F, O'Brien R. T-cell assays for the diagnosis of latent tuberculosis infection: moving the research agenda forward. Lancet Infect Dis. 2007;7(6):428-38.

44. Mack U, Migliori GB, Sester M, Rieder HL, Ehlers S, Goletti D, Bossink A, Magdorf K, Holscher C, Kampmann B, et al. LTBI: latent tuberculosis infection or lasting immune responses to M. Tuberculosis? A TBNET consensus statement. Eur Respir J. 2009;33(5):956-73.

45. Pai M, Denkinger CM, Kik SV, Rangaka MX, Zwerling A, Oxlade O, Metcalfe JZ, Cattamanchi A, Dowdy DW, Dheda K, et al. Gamma interferon release assays for detection of mycobacterium tuberculosis infection. Clin Microbiol Rev. 2014;27(1):3-20.

46. Le Roux BaR H. Geometric data analysis, from correspondence analysis to structured data analysis, Kluwer, Dordrecht. 1st ed. Netherlands: Springer; 2004

47. Roupie V, Romano M, Zhang L, Korf H, Lin MY, Franken KL, Ottenhoff TH, Klein MR, Huygen K. Immunogenicity of eight dormancy regulon-encoded proteins of mycobacterium tuberculosis in DNA-vaccinated and tuberculosis-infected mice. Infect Immun. 2007;75(2):941-9.

48. Mensah Gl, Addo KK, Tetteh JA, Sowah S, Loescher T, Geldmacher C, Jackson-Sillah D. Cytokine response to selected MTB antigens in Ghanaian TB patients, before and at 2 weeks of anti-TB therapy is characterized by high expression of IFN- $\gamma$ and Granzyme B and inter-individual variation. BMC Infect Dis. 2014;14:495.

49. Chegou NN, Black GF, Loxton AG, Stanley K, Essone PN, Klein MR, Parida SK, Kaufmann SH, Doherty TM, Friggen AH, et al. Potential of novel mycobacterium tuberculosis infection phase-dependent antigens in the diagnosis of TB disease in a high burden setting. BMC Infect Dis. 2012;12:10.

50. Gupta RK, Srivastava BS, Srivastava R. Comparative expression analysis of rpf-like genes of mycobacterium tuberculosis H37Rv under different physiological stress and growth conditions. Microbiology. 2010;156(Pt 9):2714-22.

51. Barry CE 3rd, Boshoff HI, Dartois V, Dick T, Ehrt S, Flynn J, Schnappinger D, Wilkinson RJ, Young D. The spectrum of latent tuberculosis: rethinking the biology and intervention strategies. Nat Rev Microbiol. 2009;7(12):845-55.

52. Young DB, Gideon HP, Wilkinson RJ. Eliminating latent tuberculosis. Trends Microbiol. 2009;17(5):183-8.

53. Ravn P, Demissie A, Eguale T, Wondwosson H, Lein D, Amoudy HA, Mustafa AS, Jensen AK, Holm A, Rosenkrands I, et al. Human T cell responses to the ESAT-6 antigen from mycobacterium tuberculosis. J Infect Dis. 1999;179(3):637-45.

54. Rogerson BJ, Jung YJ, LaCourse R, Ryan L, Enright N, North RJ. Expression levels of mycobacterium tuberculosis antigen-encoding genes versus production levels of antigen-specific $T$ cells during stationary level lung infection in mice. Immunology. 2006;118:195-201.

55. Cehovin A, Cliff JM, Hill PC, Brookes RH, Dockrell HM. Extended culture enhances sensitivity of a gamma interferon assay for latent mycobacterium tuberculosis infection. Clin Vaccine Immunol. 2007;14(6):796-8.

56. Leyten EM, Arend SM, Prins C, Cobelens FG, Ottenhoff TH, van Dissel JT. Discrepancy between mycobacterium tuberculosis-specific gamma interferon release assays using short and prolonged in vitro incubation. Clin Vaccine Immunol. 2007;14(7):880-5.

57. Hanekom WA, Dockrell HM, Ottenhoff TH, Doherty TM, Fletcher H, McShane H, Weichold FF, Hoft DF, Parida SK, Fruth UJ. Immunological outcomes of new tuberculosis vaccine trials: WHO panel recommendations. PLOS Med. 2008;5(7):e145.

58. Rueda CM, Marin ND, Garcia LF, Rojas M. Characterization of CD4 and CD8 T cells producing IFN-gamma in human latent and active tuberculosis. Tuberculosis (Edinb). 2010;90(6):346-53.

59. Marin ND, Paris SC, Rojas M, Garcia LF. Reduced frequency of memory $T$ cells and increased Th17 responses in patients with active tuberculosis. Clin Vaccine Immunol. 2012;19(10):1667-76. 